Article

\title{
Online Tool Wear Monitoring by the Analysis of Cutting Forces in Transient State for Dry Machining of Ti6Al4V Alloy
}

\author{
Yezika Sánchez Hernández, F. Javier Trujillo Vilches ${ }^{\circledR}$, Carolina Bermudo Gamboa *(i) and \\ Lorenzo Sevilla Hurtado (D) \\ Department of Manufacturing Engineering, EEI, University of Malaga, C/Dr. Ortiz Ramos s/n, 29071 Malaga, \\ Spain; yezika.sanchez@uma.es (Y.S.H.); Trujillov@uma.es (F.J.T.V.); lsevilla@uma.es (L.S.H.) \\ * Correspondence: bgamboa@uma.es; Tel.: +34-951-952-245
}

Received: 27 August 2019; Accepted: 16 September 2019; Published: 17 September 2019

\begin{abstract}
In this work, the analysis of the cutting speed and feed rate influence on tool wear and cutting forces in Ti6Al4V alloy dry machining is presented. The study has been focused on the machining in a transient state. The tool wear mechanisms, tool wear intensity and cutting forces evolution have been analyzed as a function of the cutting parameters. Experimental results show that the main cutting force amplitude exhibits a general trend to increase with both cutting parameters. Crater wear was more evident at high cutting speeds, whereas flank wear was present on the whole interval of the cutting parameters analyzed. Furthermore, the cutting speed shows a slightly higher influence on crater wear and the feed rate shows a higher influence on flank wear. Finally, several experimental parametric models have been obtained. These models allow predicting the evolution of crater and flank tool wear, as well as the cutting forces, as a function of the cutting parameters. Additionally, a model that allows monitoring the tool wear on the machining transient state as a function of the main cutting force amplitude has been developed.
\end{abstract}

Keywords: titanium alloys; cutting forces; dry machining; tool wear; transient state machining; online monitoring

\section{Introduction}

Titanium alloys are one of the most used commercial aerospace structural materials. Their high strength to weight ratio, corrosion resistance at high temperature, high stiffness, good fracture toughness and fatigue resistance make titanium alloys an excellent alternative to steels and aluminum alloys in airframe and engine applications [1,2]. Among the different titanium alloys, Ti6Al4V ( $\alpha+\beta$ alloy) is widely used for airframe structure manufacturing, such as window frames and gas turbine engine components (e.g., blades and discs for the fan and compressor) [3]. Despite their good physical-chemical properties, these alloys are classified within materials with low machinability [4]. Their low thermal conductivity and high chemical reactivity result in high temperatures along the cutting area and fast tool wear, which reduce tool life considerably. In addition, their low elasticity modulus, together with serrated chip production, lead to chattering and tool vibration, which may adversely affect the surface integrity of the machined parts $[5,6]$.

The aforementioned problems are increased when machining is performed under total absence of cutting fluids [7]. Until recent years, metalworking fluids (MWFs) have been commonly used to reduce friction on the tool-workpiece contact area, as well as to prevent excessive heat generation. Notwithstanding, the current trend is to reduce or eliminate the use of these MWFs due to social, economic and environmental aspects [8]. Methods based on minimum quantity of lubrication (MQL) 
or minimum quantity of cooling lubrication (MQCL) are good alternatives [9]. However, the best way to totally reduce the negative effects of MWFs is to completely eliminate them from the process (so-called dry machining). Dry machining reduces environmental pollution and minimizes health risk. However, these kinds of processes result in a faster tool wear and surface integrity degradation $[10,11]$. A correct cutting parameters selection is essential to improve the quality of these processes, not only from a functional perspective but also from an economic point of view [12,13]. Cutting speed, feed rate and cutting depth affect several aspects of the machining process, like the cutting area temperature, tool wear, built up edge (BUE) formation, cutting forces and surface quality, among others [14].

Moreover, cutting forces directly influence the surface integrity, system vibration, cutting power and tool life [15]. Both static and dynamic cutting force components are affected by cutting parameters. Cutting speed seems to be the most influential parameter in the static component. At the beginning of machining, cutting speed increments result in cutting force reduction. The low thermal conductivity of Ti6Al4V alloy leads to fast temperature increasing on the cutting area and the process becomes more adiabatic. As a consequence, the material softens, and it is more easily deformed. However, these cutting speed increments give rise to higher tool wear that may result in a cutting force increment. Therefore, there is an evolution along the cutting time that can be used to stablish a tool life criterion. Increments in cutting depth or feed rate negatively affect the cutting force, increasing its value, but it has been determined that their influence is much lower compared with the cutting speed influence [16,17]. With regard to the force dynamic component, frequency and amplitude are modified by the cutting parameters. Cutting speed increments result in higher frequency and lower amplitude, whereas feed rate increments reduce frequency (higher chip segment width) and increase force fluctuation. It has been shown that cutting depth is not relevant in the frequency analysis. However, significant amplitude increments are observed when cutting depth is increased [2,18].

Concerning tool wear, high temperatures and stresses close to the cutting area are responsible for a fast tool damage. For Ti6Al4V alloy, the main wear mechanisms are adhesion and diffusion, followed by coating delamination [18-20]. Both crater and flank wear are present during the machining of this alloy. On one hand, the chip sliding along the rake face gives rise to material adhesion on the tool. The alloy's low thermal conductivity quickly increases the temperature on the cutting area, resulting in fast chemical reactions that are responsible for the crater wear (diffusion from the work part (Ti, Al and V) to the cutting tool (W, Co and C)) [21-23]. On the other hand, flank wear is occasioned by the erosion of small fragments from the tool, due to material adhesion and its subsequent fracture that finally leads to a coating chipping. Nevertheless, crater wear is more evident when high cutting speeds are used, whereas flank wear is present in a wider range, even at low cutting speeds. Therefore, flank wear is more critical when considering tool life [24,25].

Tool wear and tool life are very important factors to take into account in the production cost and the functionality of machined parts. Consequently, the online monitoring of becomes a topic of high interest [26]. A large quantity of studies has been developed concerning reliable tool condition monitoring systems (TCMS). Several methods are used to predict the cutting tool state, based on acoustic emission, tool temperature, cutting forces, vibration, ultrasonic and optical measurements, workpiece surface finish quality, etc. [27,28]. Cutting force-based systems allow a quick response in real time. In addition, the location and the wear mechanism may affect the dynamic behavior of different force signals and therefore, the cutting forces' dynamic behavior may be correlated to tool wear [2,29]. The cutting forces' steady state analysis may be good enough for stable machining processes in which a long continuous or regularly segmented chip is produced [30]. Nevertheless, the transition from the transient beginning to the steady state plays a very important role when a serrated chip is formed, as in machining of titanium alloys [31,32].

Due to the large number of variables involved in machining, the development of analytical models that explain these alloys' behavior during the cutting process becomes a very complex task [33]. Thus, the use of numerical models (most of them based on finite element methods (FEM)) has become a widely used alternative to optimize cutting conditions [3,34]. However, FEM is not yet sufficiently 
accurate and often underestimates or overestimates the experimental results [16,33,35-37]. Accordingly, experimental models, in spite of their cost and development time, are effective to improve the numerical methods [38,39]. Thus, obtaining experimental parametric models to predict the Ti6Al4V alloy behavior during the machining transient state might be of great help to optimize the machining process.

The cutting parameters influence on cutting forces and tool wear during the steady state, during dry machining of this alloy, has been extensively studied. In addition, several models, which relate the tool wear and cutting forces with the cutting parameters (in the steady state), can be found in the literature $[14,17,18]$. Notwithstanding, there is a lack of research focused on the analysis of the transient state and in obtaining models that may relate these output variables with each other and with the cutting parameters. The behavior of these variables may differ from that shown in the steady state. Hence, these models can provide useful information about the behavior of the alloy in the first instants of machining. Therefore, in this work, the analysis of cutting speed and feed rate influence on tool wear and cutting forces in Ti6Al4V alloy dry machining, during the transient state, has been carried out. More specifically, the tool wear mechanisms, tool wear intensity and cutting forces' evolution have been analyzed as a function of cutting parameters. In addition, several experimental parametric models have been obtained. These models allow predicting the crater and flank wear evolution, as well as the cutting forces, as a function of the cutting parameters in the transient state machining. Finally, a model that allows the tool wear monitoring as a function of the cutting force in the early instants of machining has been developed. These models can provide understanding of the physical phenomena that occurs in the transient state under the studied conditions and as a result also facilitate the comprehension of the obtained experimental results of this work.

\section{Materials and Experimental Procedure}

The experimental procedure was designed to evaluate the cutting parameters' influence on tool wear and cutting forces, during the Ti6Al4V alloy transient state machining. In order to do that, several turning tests were carried out. The composition of the tested alloy obtained by arc atomic emission spectroscopy (AES), is shown in Table 1.

Table 1. Machined alloy composition (mass \%).

\begin{tabular}{cccccccc}
\hline Alloy & $\mathbf{C}$ & Fe & N & O & Al & V & Ti \\
\hline Ti6Al4V & 0.80 & 0.164 & 0.05 & 0.05 & 5.47 & 4.09 & Rest \\
\hline
\end{tabular}

Table 2 shows the cutting parameter values selected to perform the turning tests, based on industrial requirements $[18,40]$. One test was carried out for each cutting parameter combination (cutting speed $\left(v_{c}\right)$, feed rate $(f)$ and cutting depth $\left(a_{p}\right)$ ). Fifteen repetitions of each test were performed, in order to ensure the repeatability of the experimental results. Therefore, a total of 180 tests were carried out.

Table 2. Tested cutting parameter values.

\begin{tabular}{ccc}
\hline$f(\mathrm{~mm} / \mathrm{r})$ & $v_{c}(\mathrm{~m} / \mathrm{min})$ & $a_{p}(\mathrm{~mm})$ \\
\hline 0.05 & 30 & \\
0.10 & 65 & 1 \\
0.20 & 125 & \\
0.30 & & \\
\hline
\end{tabular}

Machining processes are usually oblique cutting processes which involve a large set of geometrical parameters, making the processes more difficult to understand. So, in order to simplify the analysis, an orthogonal cutting setup has been designed as shown in Figure 1 [2,41]. Thereby, the experimental results may be compared with the classic analytical models. This design has been explained in a parallel research related to the chip morphology analysis [13]. 


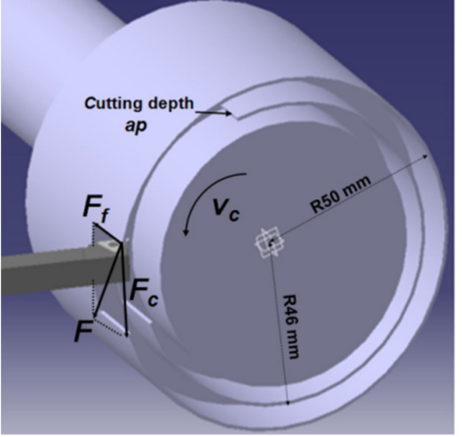

(a)

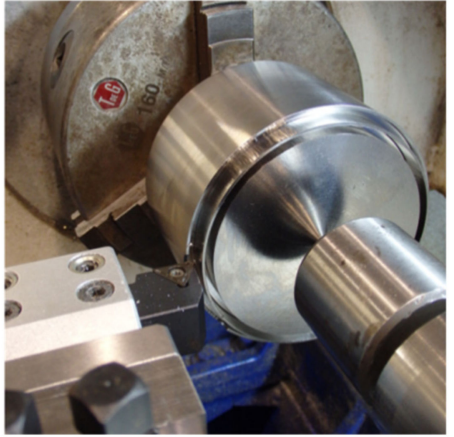

(b)

Figure 1. (a) Schematic orthogonal cutting; (b) tailor-made test specimen geometry.

The specimen was designed with a tailored geometry to maintain orthogonal conditions along the test and also to achieve different cutting speed and feed rate ranges. Different grooving operations were carried out on a bar $(L=170 \mathrm{~mm}, D=105 \mathrm{~mm})$ to get a tubular geometry with two crowns, corresponding to two previously machined diameters. Each crown was pre-machined to get a wall of 1 $\mathrm{mm}$ thickness (wall thickness corresponds to cutting depth, $a_{p}$, which was kept constant). The width of each crown was equivalent to the total machining length that corresponds to a certain combination of cutting parameters. Additionally, a relief zone was established (eliminating a sector of the crowns, (Figure 2a)), to ensure that the spindle had reached a permanent regime [13].

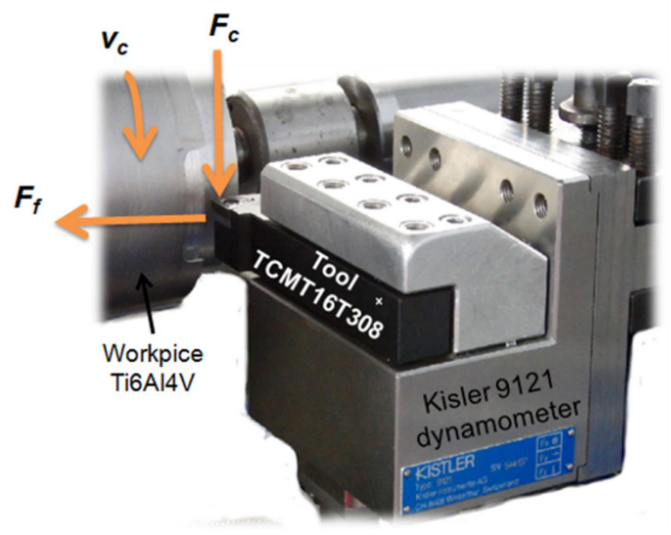

(a)

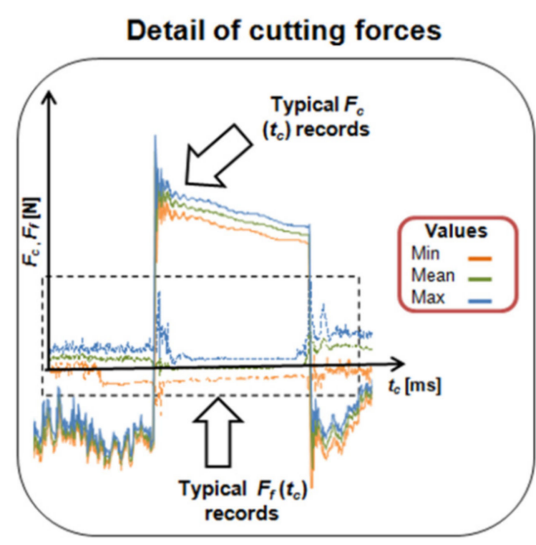

(b)

Figure 2. (a) Cutting force acquisition system; (b) typical signals $F_{c}\left(t_{c}\right)$ and $F_{f}\left(t_{c}\right)$.

The tests were conducted in a turning center, in dry conditions. A combination of coated $\left(\mathrm{TiCN} / \mathrm{Al}_{2} \mathrm{O}_{3}\right)$ WC-Co inserts (ISO reference TCMT 16T308-F1, Fagersta, Sweden) and a tool holder (STGCL 2020K16, Dalseong-gun, Daegu, Korea) was used, providing a cutting setup very close to orthogonal conditions (major cutting edge angle, $\kappa_{\mathrm{r}}=90^{\circ}$; inclination angle, $\lambda \approx 0^{\circ}$; rake angle, $\gamma=-6^{\circ}$ ). A new tool was used in each cutting test, in order to maintain the same initial properties.

The main cutting force $\left(F_{c}\right)$ and feed force components $\left(F_{f}\right)$ were monitored online throughout the machining transient state. For this purpose, a piezoelectric sensor dynamometer, 9121 Kistler, Jonsered, Sweden (measuring only in two directions), an amplifier and dynamic signal analyzer (based on Fast Fourier Transform (FFT)) and a Pulse Labshop data acquisition system were used. The sampling frequency was kept at a relatively high level $(10 \mathrm{kHz})$ in order to analyze the transient state. Figure 2 shows this experimental setup and an example of the typical cutting forces records as a function of cutting time $\left(t_{c}\right)$, in the first stage of the machining (quasi-steady state).

The dynamic signal components $\left(F_{c}\right.$ and $F_{f}$ ) have been represented by minimum, arithmetic average and maximum from 15 test repetitions (equivalent to a total machining length of 15 revolutions) [13]. 
Figure 3 shows a typical $F_{c}$ dynamic signal record as a function of $t_{c}$, along the machining transient state. The signal can be divided in five different zones. Zone 1 corresponds to the period $t_{1}$ in which the tool moves through the relief area without cutting; Zone 2 represents a very short period, $t_{2}$, in which $F_{c}$ oscillates from the first significant changes to a maximum peak due to the first tool indentation; Zone 3 displays the period $t_{3}$ in which the maximum $F_{c}$ value is reached. In this stage, the material starts to slide through on the tool rake face. Zone $4, t_{4}$, limits the quasi-steady force interval to an instant before the end of the cutting process. Zone 5 represents the final stage of the cutting process, $t_{5}$. Therefore, the total machining time, $t_{c}$, is represented by the total time consumed in the five zones, as shown in Equation (1).

$$
t_{c}=t_{1}+t_{2}+t_{3}+t_{4}+t_{5}
$$

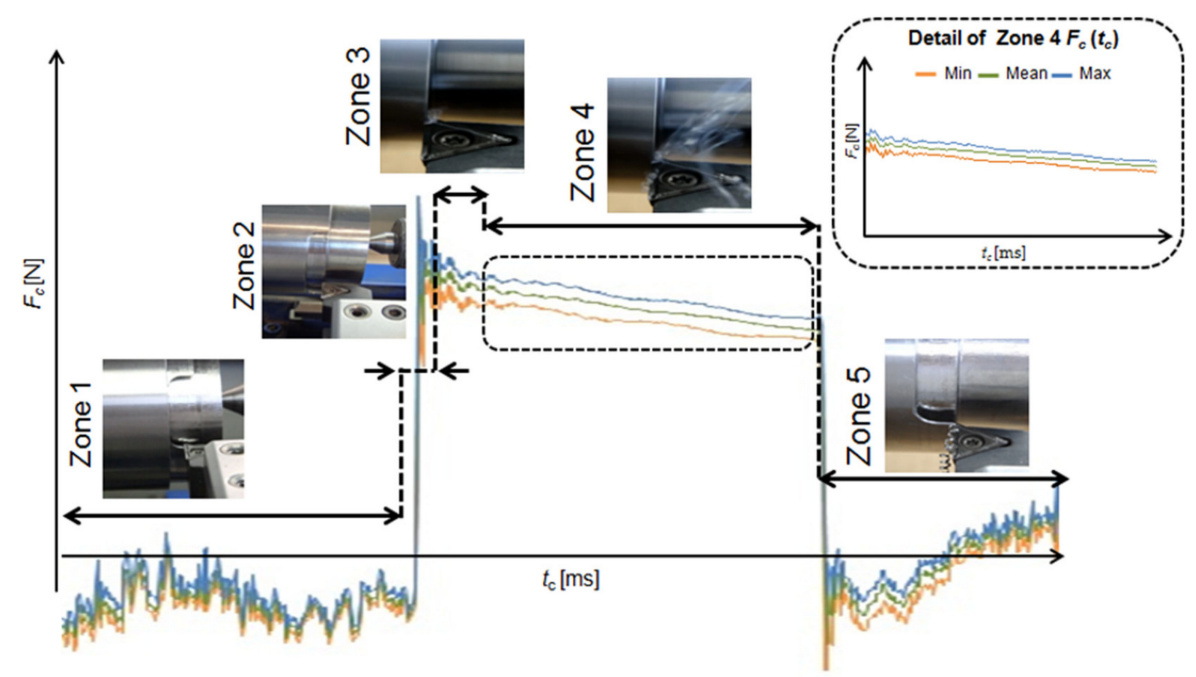

Figure 3. Different zones along the main cutting force dynamic signal $F_{c}\left(t_{c}\right)$.

In this work, only Zone 4 has been considered to evaluate the cutting forces' amplitudes, in order to eliminate the beginning and ending effects of the process. At the same time, this stage represents the cutting force $\left(F_{c}\right)$ during the turning process. This stage is very important for a better understanding of the thermomechanical effects and plastic deformation on the cutting area.

Stereoscopic optical microscopy (SOM) techniques were used to control tool crater and flank wear intensity. The parameters used to evaluate tool wear were the flank wear width $(V B)$ as shown in Figure $4 \mathrm{a}$, and the crater wear area $(K A)$ as shown in Figure $4 \mathrm{~b}$ [22,42]. A metallurgical microscope (EPIHOT 280 NIKON, Tokio, Japan) was used in order to measure these parameters. All the images were obtained using a CF Infinity Optical System, Tokio, Japan (1.5× to 400×) and the measurements were carried out using a digital image processing software (Omnimet BUEHLER, Lake Bluff, IL, USA).

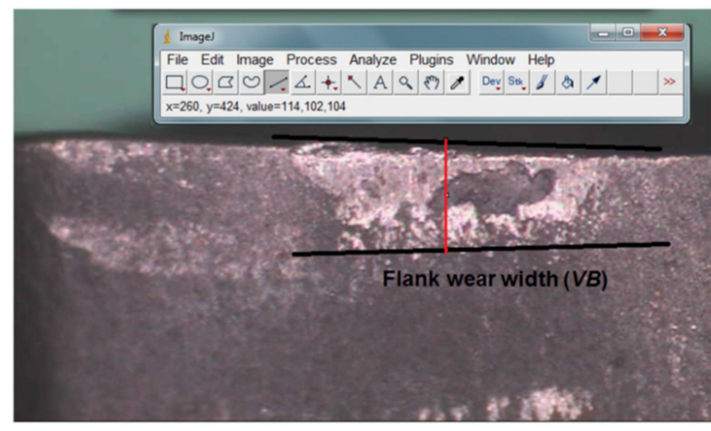

(a)

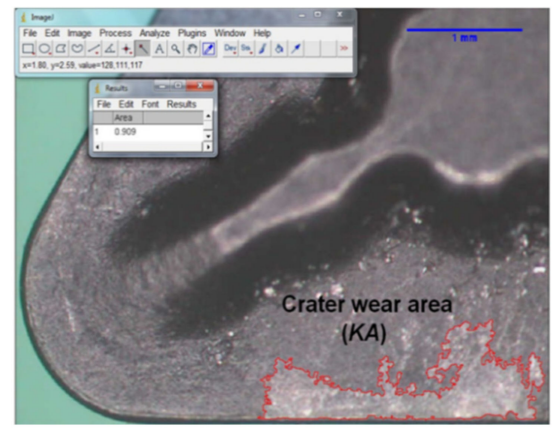

(b)

Figure 4. (a) Tool flank wear and (b) crater wear (stereoscopic optical microscopy (SOM) images 30×). 


\section{Results and Discussion}

\subsection{Dynamic Cutting Forces Amplitude Analysis}

Figure 5 plots $F_{\mathcal{c}}$ and $F_{f}$ amplitude average values as a function of $v_{\mathcal{C}}$ and $f$. These average values have been obtained from 15 repetitions for each combination of cutting parameters (machining length equivalent to 15 turns).

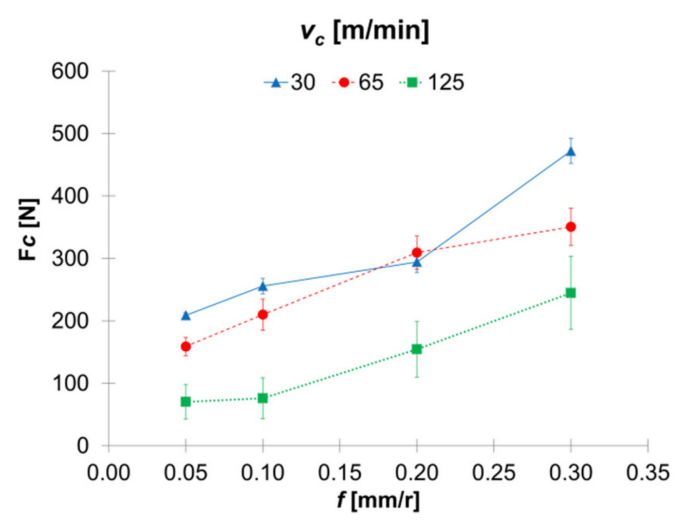

(a)

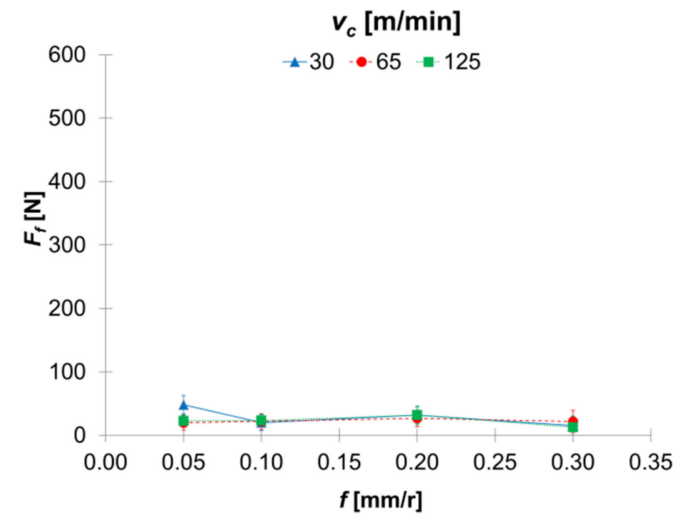

(b)

Figure 5. $F_{\mathcal{c}}$ and $F_{f}$ amplitude average values as a function of $v_{\mathcal{C}}$ and $f(\mathbf{a}) F_{\mathcal{C}}=\left(f, v_{\mathcal{C}}\right) ;(\mathbf{b}) F_{f}=\left(f, v_{\mathcal{C}}\right)$.

No significant $F_{f}$ changes have been noted as a function of $v_{c}$ and $f$, remaining more or less constant in a wide range of cutting parameters values. Only for $f=0.05 \mathrm{~mm} / \mathrm{r}$, a slightly $F_{f}$ increase is shown. This increment is more noticeable for $v_{c}=30 \mathrm{~m} / \mathrm{min}$. This fact may be explained considering the lower temperature and material softening values obtained when very low $f$ is used, together with higher vibrations levels at low $v_{c}$.

The main cutting force, $F_{c}$, shows significantly higher values than the feed force, $F_{f}$. In addition, $F_{c}$ is more sensitive to cutting parameters changes (both $v_{c}$ and $f$ ) than $F_{f}$. This is due to the fact that, in the first machining instants, the material impact on the rake face becomes more relevant than chip friction on the rake and flank faces. Then, $F_{f}$ (which depends mainly on friction on the flank face $[2,14]$ ) shows a much lower value than $F_{c}$. Therefore, $F_{c}$ is the dominant force component and as a result it has been selected to analyze the tool wear behavior.

A general trend to decrease $F_{c}$ with $v_{c}$ is observed. The minimum $F_{c}$ values are always obtained for $v_{c}=125 \mathrm{~m} / \mathrm{min}$ regardless of $f$, whereas the maximum $F_{c}$ is obtained for $v_{c}=30 \mathrm{~m} / \mathrm{min}$ (for most $f$ ), reaching differences between 2.5 to 3 times its value. These differences are less noticeable between $v_{c}=65$ and $30 \mathrm{~m} / \mathrm{min}$, even when reaching similar values for $f=0.2 \mathrm{~mm} / \mathrm{r}$. Only for $f=0.30 \mathrm{~mm} / \mathrm{r}, F_{c}$ becomes 2.5 times higher for $v_{\mathcal{C}}=30 \mathrm{~m} / \mathrm{min}$ than with the other $v_{c}$.

Regarding $f, F_{c}$ shows a general trend to increase when $f$ is increased, regardless the cutting speed applied. Notwithstanding, its influence seems to be slightly lower than $v_{\mathcal{c}}$. The differences oscillate between 1.7 (for $v_{\mathcal{C}}=30 \mathrm{~m} / \mathrm{min}$ ) and 2.6 times its value (for $v_{\mathcal{C}}=125 \mathrm{~m} / \mathrm{min}$ ). Therefore, combinations of low $v_{\mathcal{C}}$ and high $f$ results in the highest $F_{c}$.

The low thermal conductivity of this alloy results in fast temperature increasing close to the cutting area, as previously mentioned. Consequently, the alloy's plastic behavior is modified, giving rise to a material softening $[1,11]$. Therefore, the energy needed to deform the material is reduced. This fact is enhanced by cutting speed increments. In addition, lower feed rates imply lower chip sections and, therefore, lower cutting forces $[17,18]$.

It is necessary to point out that the founded trend for the dynamic main force amplitude (regarding cutting parameters) is in good agreement with the trend observed in previous research for the static component $[2,16]$. Nevertheless, the absolute values are much higher in the quasi-steady state. The material softening grows along the cutting time, until cutting force stabilizes in a lower value. 


\subsection{Tool Wear Online Monitoring}

Table 3 shows the SOM images obtained from the tool rake, flank face and tool edge and classified as a function of the cutting parameters. These images allow a first qualitative approach to the tool wear mechanism and its intensity. The images correspond to the tool after performing a machining length equivalent to 15 turns.

Table 3. SOM images (30x) of the tools used.

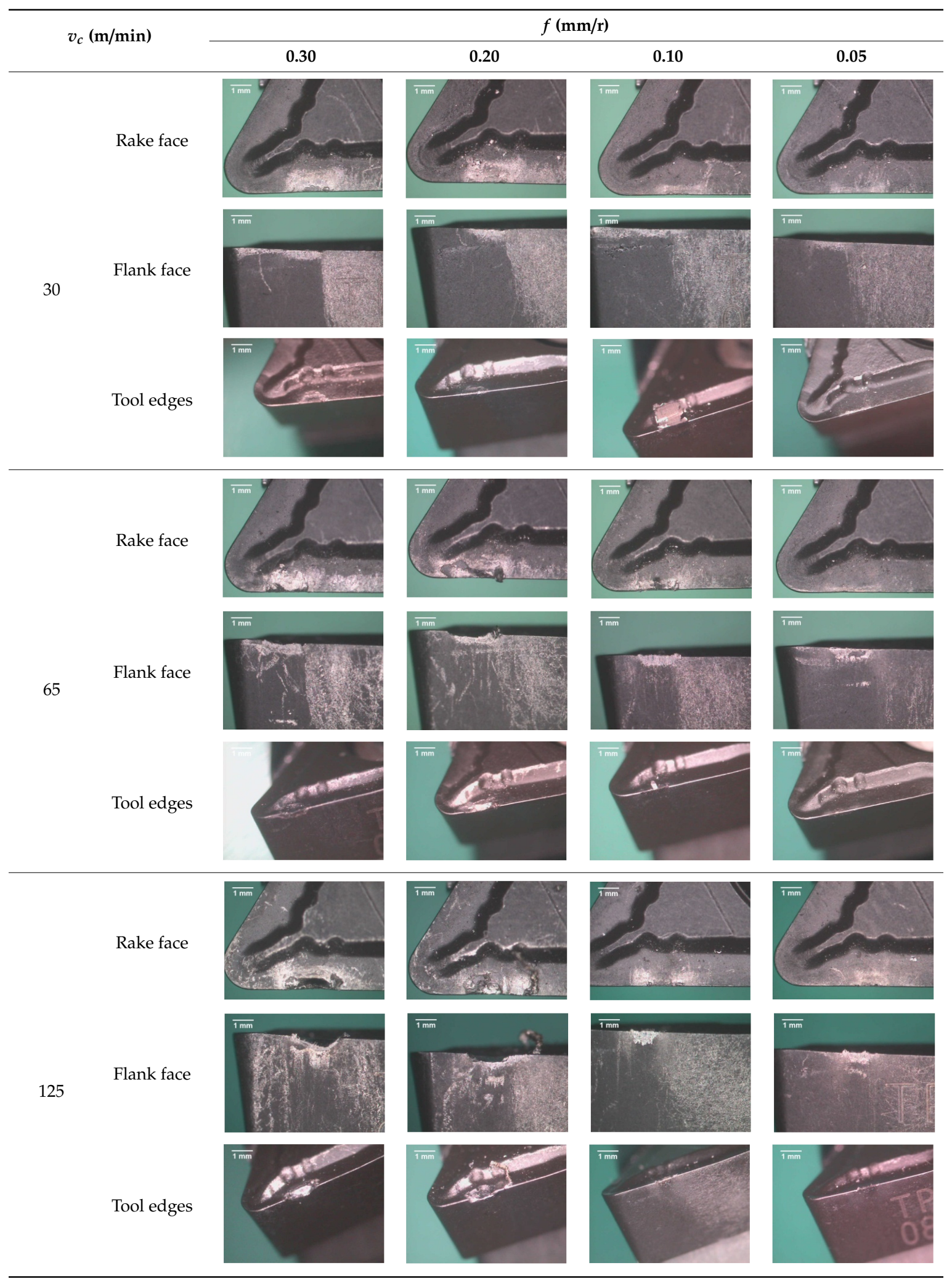


These images show that the crater wear increases with $v_{c}$. The highest intensity is obtained for $v_{c}=125 \mathrm{~m} / \mathrm{min}$. This wear on the tool rake face is less evident when low $f(0.05-0.10 \mathrm{~mm} / \mathrm{r})$ and $v_{c}$ $\left(30 \mathrm{~m} / \mathrm{min}\right.$ ) are used. Its intensity is enhanced when $f$ is increased. High $f$ and $v_{c}$ give rise to fast temperature increment that results in diffusion wear and crater formation $[17,23]$. Therefore, this wear mechanism is increased with $v_{c}$ and $f$.

In addition, a secondary adhesion wear phenomenon is observed on the tool rake face, at high $v_{\mathcal{C}}(65-125 \mathrm{~m} / \mathrm{min})$ and $f(0.20-0.30 \mathrm{~mm} / \mathrm{r})$. High $f$ results in high pressures in the cutting area that, together with high temperatures at high cutting speed, facilitates the built up layer (BUL) formation, due to thermo-mechanical effects.

Flank wear is present throughout the cutting speed range analyzed, even at low $v_{\mathcal{c}}(30 \mathrm{~m} / \mathrm{min})$. Its intensity is increased with $v_{\mathcal{c}}$. This increment is much more evident on the high $f$ range $(0.20-0.30 \mathrm{~mm} / \mathrm{r})$. Hence, $f$ increments result in higher flank wear intensity, increasing $v_{\mathcal{c}}$ negative effect.

This wear is also a consequence of thermo-mechanical effects on the cutting area. High pressures and temperatures cause material adhesion on the tool edge (built up edge, BUE). This BUE is unstable and tend to detach. As a result, the tool breaks and material fragments from the tool are incorporated to the chip $[1,21]$. The BUE formation is clearly observed for high $f$ values $(0.20-0.30 \mathrm{~mm} / \mathrm{r})$, regardless the $v_{c}$ used. For $f=0.10 \mathrm{~mm} / \mathrm{r}$, BUE shows lower intensity and it is observed only at low $v_{\mathcal{c}}$. For $f=0.05 \mathrm{~mm} / \mathrm{r}$, BUE is practically not present.

In addition, an abrasion phenomenon on the flank face is observed. It is present in the whole $v_{c}$ range tested and is increased with $f$. On one hand, this abrasion is a consequence of the friction between the chip (when it rolls over itself) and the tool. The chip section is increased with $f$ and, consequently, the abrasion area increases. On the other hand, this abrasion is also caused by the erosion of small fragments from the tool, due to material adhesion to the tool surface and subsequent detachment or fracture [1].

Regarding the tool wear intensity, Figure 6 shows the $V B$ and $K A$ mean values evolution as a function of the cutting speed and feed rate. A general trend to increase $V B$ with $v_{\mathcal{C}}$ and $f$ is observed (Figure 6a). The highest values are obtained for $v_{c}=125 \mathrm{~m} / \mathrm{min}$, regardless $f$. Within the lowest $f$ range $(0.05-0.10 \mathrm{~mm} / \mathrm{r})$, for $v_{c}=65$ and $125 \mathrm{~m} / \mathrm{min}$, feed rate becomes more important than cutting speed. However, for lower $v_{\mathcal{C}}\left(v_{\mathcal{C}}=30 \mathrm{~m} / \mathrm{min}\right), f$ becomes less relevant. Within the intermediate $f$ interval $(0.10-0.20 \mathrm{~mm} / \mathrm{r})$, the highest $V B$ increments are observed for $v_{c}=30 \mathrm{~m} / \mathrm{min}$, whereas for 65 and $125 \mathrm{~m} / \mathrm{min}$ these increments are less noticeable. For the highest $f$ range $(0.20-0.30 \mathrm{~mm} / \mathrm{r}), f$ becomes less relevant, with $v_{c}$ being the predominant parameter.

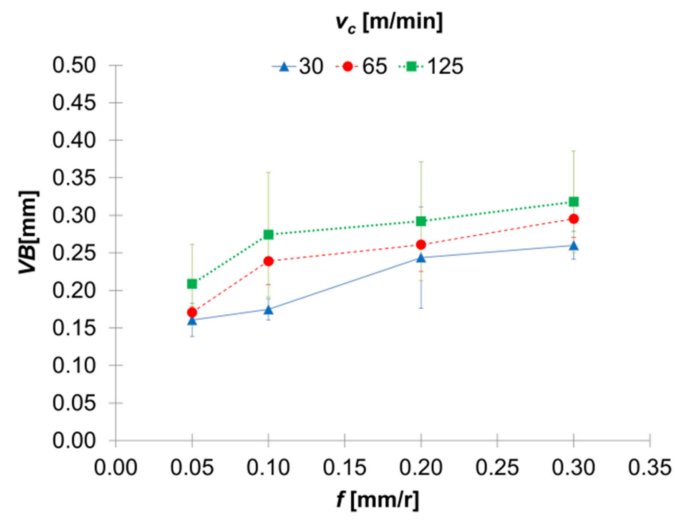

(a)

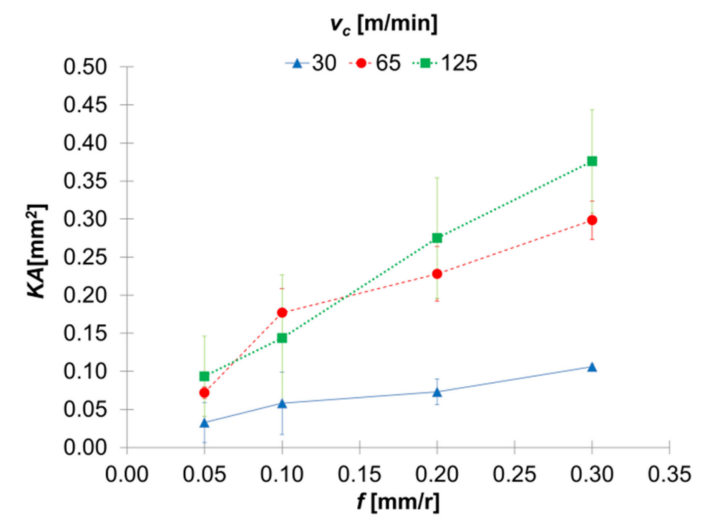

(b)

Figure 6. Tool wear intensity evolution as a function of $v_{c}$ and $f$. (a) Flank wear $(V B)$; (b) crater wear $(K A)$.

These $V B$ trends are in good agreement with the flank wear behavior previously commented. Flank wear is observed in the whole $v_{\mathcal{C}}$ range analyzed. Nevertheless, $v_{\mathcal{C}}$ seems to have less influence 
on low $f$ values, whereas both cutting parameters $\left(v_{c}\right.$ and $\left.f\right)$ have similar influence at high $f$. Therefore, $f$ shows slightly higher influence on flank wear.

In Figure $6 \mathrm{~b}, K A$ shows a general trend to increase with $v_{c}$ and $f$. This increment is lower for $v_{c}=30 \mathrm{~m} / \mathrm{min}$. The highest values are obtained for $v_{c}=125 \mathrm{~m} / \mathrm{min}$, closely followed by $v_{c}=65 \mathrm{~m} / \mathrm{min}$. The differences between these two cutting speed values are more significant within the highest $f$ range $(0.20-0.30 \mathrm{~mm} / \mathrm{r})$, whereas those differences are lower for the lowest $f$ interval $(0.05-0.10 \mathrm{~mm} / \mathrm{r})$. Even for $f=0.10 \mathrm{~mm} / \mathrm{r}$, higher $K A$ values are obtained for $v_{c}=65 \mathrm{~m} / \mathrm{min}$ than for $v_{c}=125 \mathrm{~m} / \mathrm{min}$.

Therefore, cutting speed seems to be more influential on crater wear, within the highest and lowest $f$ intervals. Only for the intermediate $f$ range, both parameters obtain similar relevance. As a result, $v_{\mathcal{C}}$ shows a slightly higher influence on crater wear than $f$. Its effect is increased by $f$, reaching the worst results when the highest $v_{c}$ and $f$ are combined. All these trends are in good agreement with the aforementioned crater wear observations.

The experimental results obtained for the cutting forces and tool wear, and their evolution with the cutting parameters, seem to indicate that it is possible to find a relationship between the dynamic main cutting force amplitude and the parameters selected to measure crater and flank wear. This fact can be visualized in Figures 7 and 8, where the superimposed experimental results for $\left(F_{\mathcal{c}}, V B\right)=f\left(v_{\mathcal{c}}, f\right)$ and $\left(F_{c}, K A\right)=f\left(v_{c}, f\right)$, respectively, are shown.

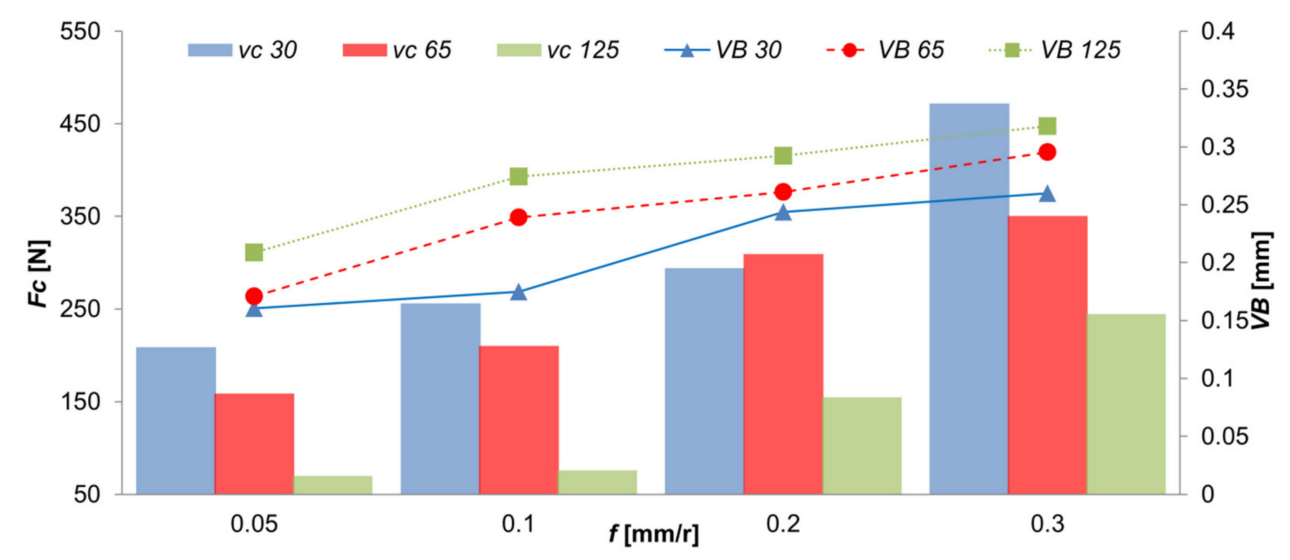

Figure 7. $F_{\mathcal{C}}$ vs. $V B$, as a function of $f$ and $v_{c}$.

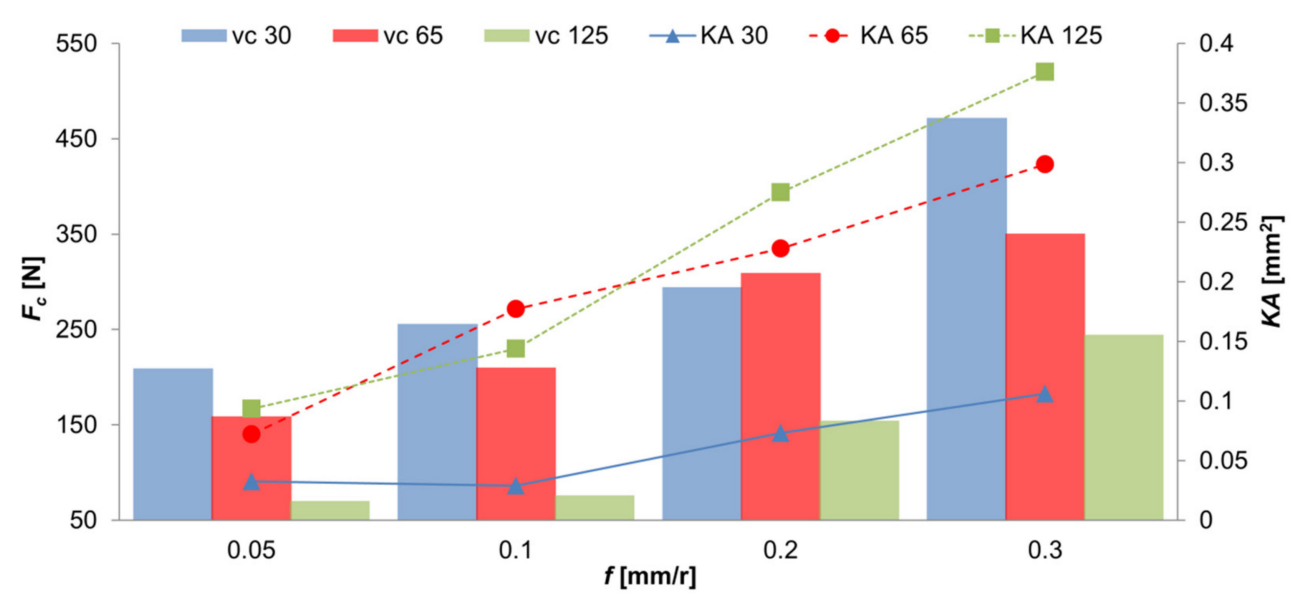

Figure 8. $F_{c}$ vs. $K A$, as a function of $f$ and $v_{c}$.

\subsection{Experimental Parametric Models}

As previously mentioned in the introduction, obtaining mathematical models from experimental data that allow predicting machining output variables as a function of cutting parameters may be very useful. If these experimental models are obtained for the first machining instants (transient state 
or quasi-steady state), in which the numerical models are usually focused, they might help to better understand the physical-chemical phenomenon produced in the cutting area. In addition, they can be useful to improve the online monitoring of output variables.

First of all, several parametric models have been obtained which predict the output variables analyzed $\left(F_{c}, V B\right.$ and $\left.K A\right)$ as a function of the cutting parameters studied (cutting speed and feed rate). Among the different models tried, a potential model has exhibited the best fit, as shown in Equation (2) [13]:

$$
\mathrm{OV}=\mathrm{K} \cdot v_{c}^{x} \cdot f^{y}
$$

In Equation (2), $O V$ is the output variable studied, with the constants being $\mathrm{K}, x$ and $y$. A multivariable linear regression has been used to fit the model. Table 4 provides the results for the constants of the model, for each output variable $(\mathrm{OV})$, as well as the adjusted determination coefficient, $\mathrm{R}^{2}$. The results of the proposed models and the experimental data are contrasted in Figure 9.

Table 4. Model coefficients.

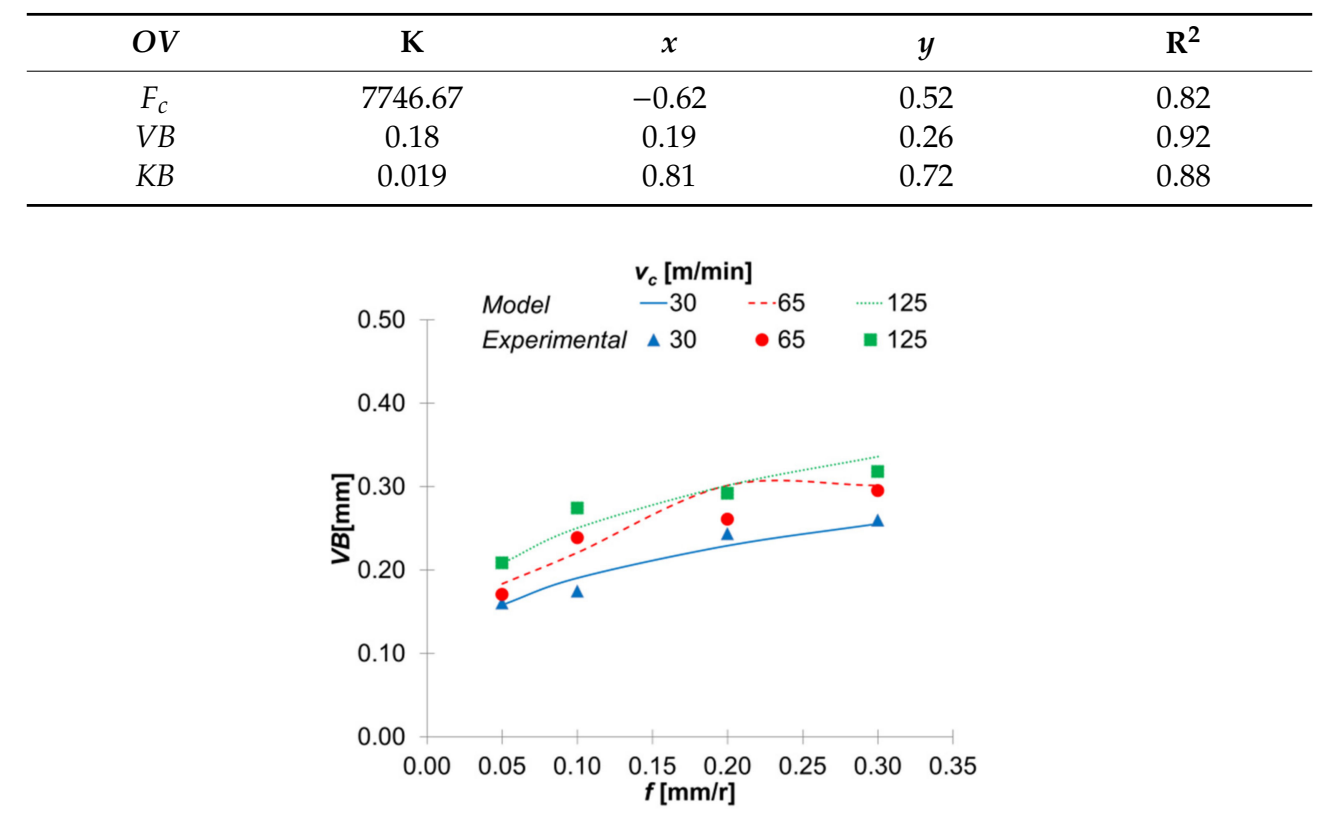

(a)

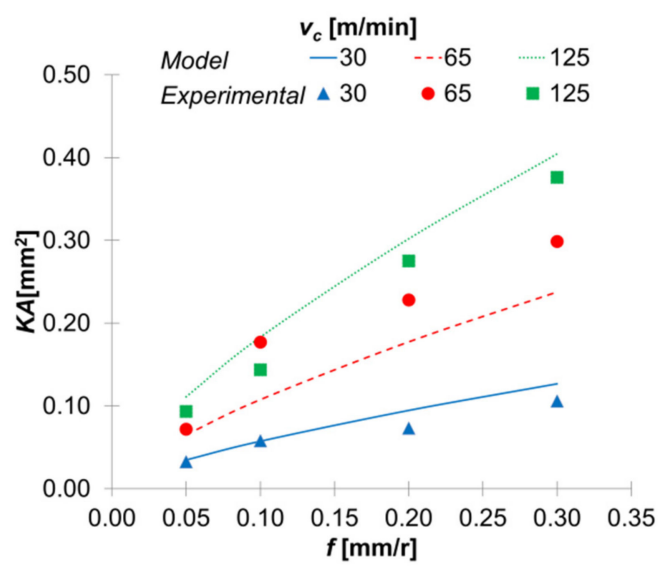

(b)

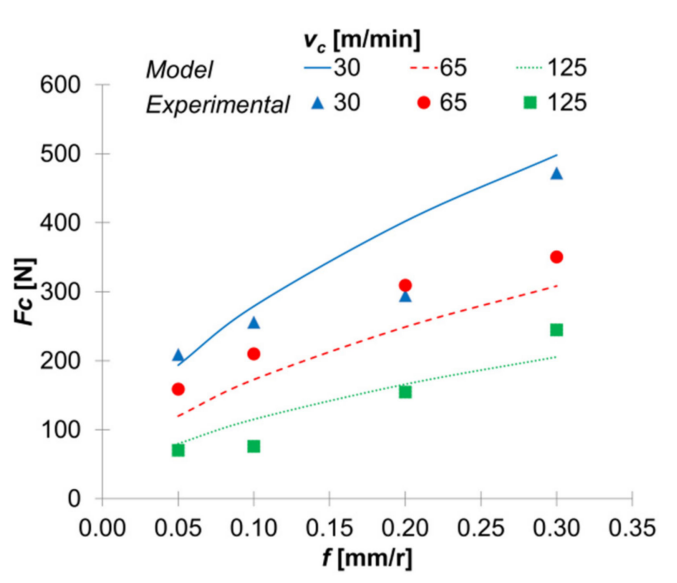

(c)

Figure 9. Experimental data vs. parametric models, for (a) $F_{c}$; (b) $V B$; and (c) $K A$.

As it can be observed in Table 4, the three parametric models show a reasonable fit. The model for $F_{c}$ shows a negative exponent for $x$ and positive one for $y$. Therefore, they indicate that $F_{c}$ decreases 
with $v_{c}$ and increases with $f$, being in good agreement with the experimental observations. In addition, both variables have a very similar weight on the $F_{c}$ value. Nevertheless, the exponent for $v_{c}$ exhibits a slightly higher value and, therefore, $v_{c}$ seems to be slightly predominant.

Regarding $V B$, as it can be seen from Figure $9 a$, both exponents are positive and, as a result, the model indicates that flank wear tends to increase with $v_{c}$ and $f$. In this case, the exponent for $f$ is higher, which indicates that $f$ shows a bit higher influence on this parameter and as a consequence, on flank wear. In addition, Figure $9 \mathrm{~b}$ shows that the $K A$ exponents are also both positive, with the values obtained being very close to each other, which indicates that crater wear increases with $v_{c}$ and $f$. However, opposite to what happens with flank wear, $v_{c}$ exhibits a slightly higher influence (higher exponent value). It is necessary to highlight that these results are in good agreement with the aforementioned experimental observations regarding flank and crater wear.

In Figure $9 \mathrm{c}$, the $F_{c}$ model shows a good fit for $v_{\mathcal{c}}=30$ and $125 \mathrm{~m} / \mathrm{min}$. Higher dispersion is found only for $v_{c}=30 \mathrm{~m} / \mathrm{min}$ and $f=0.20 \mathrm{~mm} / \mathrm{r}\left(F_{c}\right.$ is overestimated by $30 \%$ ). For $v_{c}=65 \mathrm{~m} / \mathrm{min}$, the model underestimates $F_{c}$ by $25 \%$ throughout the $f$ range.

With regard to the tool wear parameters, the model exhibits a very good fit for $V B$ throughout the whole $v_{\mathcal{C}}$ and $f$ tested intervals. In addition, the model for $K A$ (Figure $9 \mathrm{~b}$ ) shows a good fit for $v_{c}=30$ and $125 \mathrm{~m} / \mathrm{min}$. Nevertheless, it underestimates the experimental results for $v_{c}=65 \mathrm{~m} / \mathrm{min}$, from $f=0.10$ to $0.30 \mathrm{~mm} / \mathrm{r}$.

In general terms, these models show a reasonable fit. However, these models seem to be less accurate for $v_{c}=65 \mathrm{~m} / \mathrm{min}$, mainly for $F_{c}$ and $K A$. These could be explained taking into account that the indirect adhesion wear (built up edge, BUE and built up layer, BUL) is the predominant tool wear mechanism in the machining first instants $[18,19]$. The BUE and BUL formation is in an incipient state for $v_{c}=30 \mathrm{~m} / \mathrm{min}$, Table 3. Notwithstanding, for $v_{c}=65 \mathrm{~m} / \mathrm{min}$, the adhered material is more noticeable (more quantity of material can be observed in the rake face and the tool edge), but it is unstable and tends to detach from the edge and the rake face. This fact may explain the increment in the cutting forces and the underestimation of the tool wear in the model. Finally, the quantity of material adhered to the tool is higher for $v_{c}=125 \mathrm{~m} / \mathrm{min}$, and the material detaching tends to be less likely.

As previously commented, the experimental results have shown that it is possible to try a model which allows monitoring tool wear through the main cutting force amplitude in the transient state. Equations (3) and (4) show the proposed models for $V B$ and $K A$, respectively. Due to the higher influence of $f$ on $V B$ and $v_{\mathcal{C}}$ on $K A$, both cutting parameters have been included in the models. These models are a combination of the results obtained in Table 4 .

$$
\begin{aligned}
& V B=K \cdot f^{\mathrm{x}} \cdot F_{c}^{\mathrm{y}} \\
& K A=\mathrm{K} \cdot v_{c}^{\mathrm{x}} \cdot F_{c}^{\mathrm{y}}
\end{aligned}
$$

In Equations (3) and (4), K, $x$ and $y$ are constants. Table 5 provides the results obtained in the regression for these constants.

Table 5. Model coefficients.

\begin{tabular}{ccccc}
\hline$G P$ & $\mathbf{K}$ & $x$ & $y$ & $\mathbf{R}^{\mathbf{2}}$ \\
\hline$V B$ & 2.19 & 0.41 & -0.26 & 0.91 \\
$K A$ & $2.8 \times 10^{-7}$ & 1.57 & 1.22 & 0.93 \\
\hline
\end{tabular}

Figures 10 and 11 plot the model results versus the experimental data. Table 5 shows a reasonable fit for both models. This fact is also observed in Figures 10 and 11. The exponents for each proposed model (Table 5) indicate a crater and flank tool wear increment with the cutting parameters. These wear results are in good agreement with the experimental observations. On the other hand, the negative exponent for $F_{c}$ in Equation (3) indicates that $V B$ is increased when $F_{c}$ decreases. This can be explained due to the fact that this exponent includes the $v_{c}$ effect, which tends to reduce $F_{c}$. This fact is not normal 
in the steady state. Usually, the increment of the tool wear results in an increment of the cutting forces. However, as discussed in the introduction, the Ti6Al4V alloy's low thermal conductivity leads to fast temperature increasing in the cutting area and a material softening as a result. This fact results in a reduction of the cutting forces. In the machining first instants, tool wear is not enough to compensate this cutting force reduction. Therefore, a reduction of the cutting forces and an increment of tool flank wear may be compatible [2,43]. In the steady state, the effect of the tool wear is higher and the softening effect in the cutting area and an increment of tool wear results in an increment of the cutting forces.

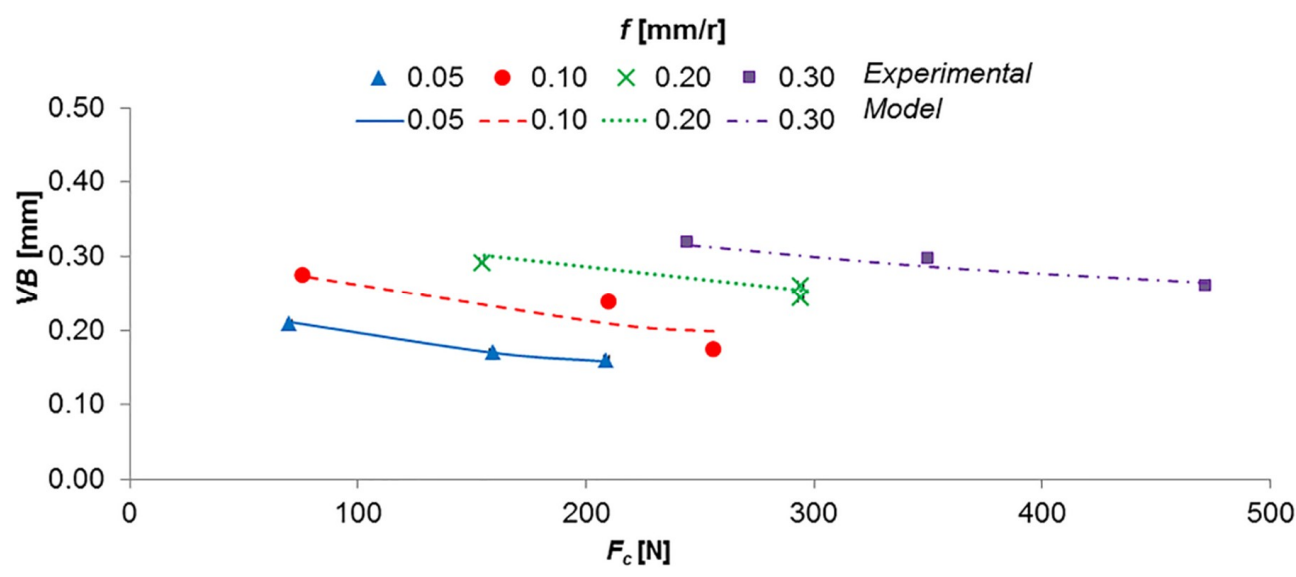

Figure 10. Experimental data vs. parametric model for $V B=f\left(f, F_{c}\right)$.

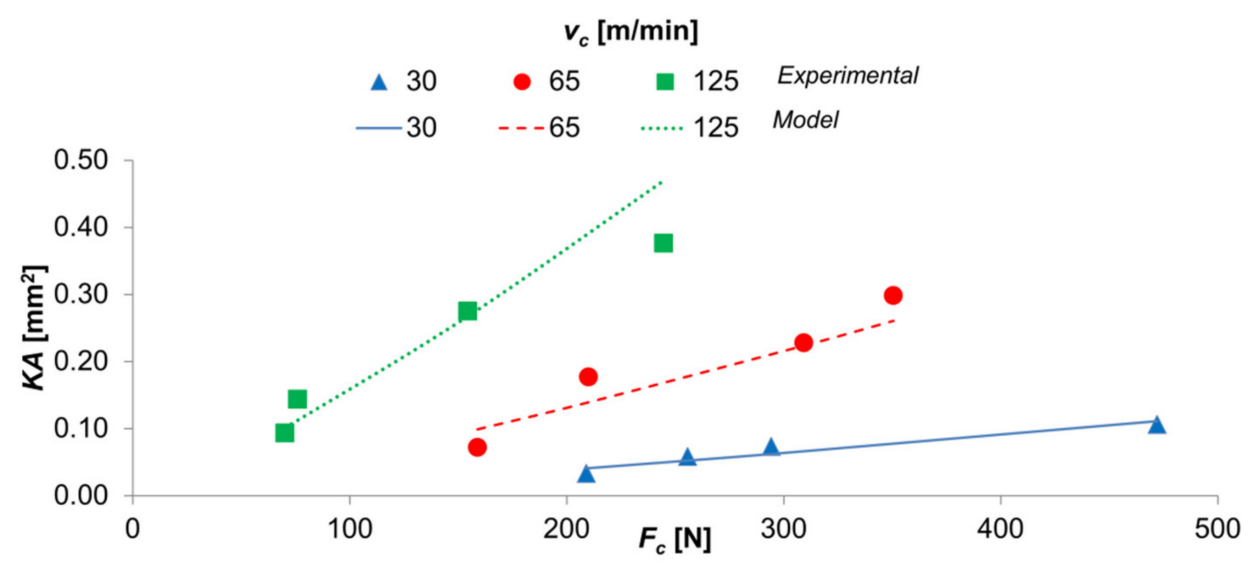

Figure 11. Experimental data vs. parametric model for $K A=f\left(v_{\mathcal{c}}, F_{c}\right)$.

On the other hand, the positive value for the $F_{c}$ exponent in Equation (4) indicates that $K A$ tends to increase with $F_{c}$. This is logical, taking into account that $F_{c}$ increases with $f$.

It is necessary to point out that these models are only valid within the range of the applied cutting parameters, the used tool, the applied cutting conditions and for the first instant of machining (transient state). The aim of the authors is not to obtain a general model that relates the studied output variables as a function of the cutting parameters for the steady state. Notwithstanding, the developed models may facilitate the understanding of the physical phenomena that occurs in the transient state and, as a result, allow a better comprehension of the experimental results.

\section{Conclusions}

In this work, the influence of the cutting speed and feed rate on the cutting forces and tool wear in dry machining of Ti6Al4V alloy has been analyzed. The study has been focused on the transient state machining, monitoring tool wear through the machining process with different cutting parameters and analyzing the cutting forces. 
The main cutting force has shown significantly higher values and more sensitive behavior related to the cutting parameters than the feed force. In addition, the main cutting force has exhibited a general trend to decrease with the cutting speed and to increase with the feed rate. Therefore, low cutting speed and high feed rate combinations have resulted in highest main cutting forces. On one hand, increments in cutting speed give rise to fast temperature increasing in the cutting area and a material softening as a result. On the other hand, feed rate reductions imply lower chip section and, therefore, lower cutting forces.

The crater wear has shown a general trend to increase with cutting speed and feed rate. Its formation has been more noticeable at high cutting speeds. High feed rates and cutting speeds give rise to fast temperature increment that results in secondary adhesion wear (built up layer), diffusion wear and crater formation, due to thermo-mechanical effects. The crater wear intensity has been quantified with the crater wear area. This parameter has shown a general trend to increase with cutting speed and feed rate. Notwithstanding, cutting speed has exhibited slightly higher influence on this parameter.

The flank wear was present throughout the cutting speed range analyzed, even at low values. Its intensity has shown a general trend to increase with both cutting parameters (cutting speed and feed). This wear is also a consequence of thermo-mechanical effects. High pressures and temperatures cause material adhesion to the tool edge (built up edge), which is unstable and tends to detach, resulting in tool breaking. The flank wear width has been the parameter used to evaluate the flank wear intensity. This parameter has exhibited a general trend to increase with both cutting parameters. However, feed rate has shown a slightly higher influence.

In addition, an abrasion phenomenon on the flank face has been observed, as a consequence of the friction between the chip and the flank face, and the erosion of small fragments from the tool.

Several experimental parametric models have been obtained to predict the main cutting force, the crater wear area and the flank wear width as a function of the cutting parameters. A potential model has exhibited a reasonable fit for the three variables studied.

Finally, a parametric potential model that relates the main cutting forces' amplitude and the tool wear has been developed. This model allows the tool wear monitoring through the main cutting force amplitude in the transient state. This model has shown a reasonable correlation with the experimental results. It is necessary to highlight that this model is only valid for the transient state, within the range of analyzed cutting parameters and under the cutting conditions described in the experimental methodology. Its general validity should be tested under different cutting conditions.

Author Contributions: Conceptualization, Y.S.H., F.J.T.V., C.B.G. and L.S.H.; Methodology, Y.S.H. and L.S.H.; Validation, Y.S.H.; Formal Analysis, Y.S.H.; Investigation, Y.S.H.; Resources, Y.S.H., F.J.T.V., C.B.G. and L.S.H.; Data Curation, Y.S.H.; Writing-Original Draft Preparation, Y.S.H., F.J.T.V. and C.B.G.; Writing-Review \& Editing, L.S.H.; Supervision, L.S.H.

Funding: This research received no external funding.

Acknowledgments: The authors want to thank the University of Malaga-Andalucía Tech, International Campus of Excellence, for its financial support of this paper.

Conflicts of Interest: The authors declare no conflict of interest.

\section{References}

1. López de lacalle, L.; Pérez, J.; Llorente, J.; Sánchez, J. Advanced cutting conditions for the milling of aeronautical alloys. J. Mater. Process. Technol. 2000, 100, 1-11. [CrossRef]

2. Veiga, C.; Davim, J.P.; Loureiro, A.J.R. Properties and applications of titanium alloys: A brief review. Rev. Adv. Mater. Sci. 2012, 32, 133-148.

3. Zhu, L.; Li, N.; Childs, P.R.N. Light-weighting in aerospace component and system design. Propuls. Power Res. 2018, 7, 103-119. [CrossRef]

4. Hosseini, A.; Kishawy, H. Machining of Titanium Alloys; Materials Forming, Machining and Tribology; Davim, J.P., Ed.; Springer: Berlin/Heidelberg, Germany, 2014; ISBN 978-3-662-43901-2. 
5. Ezugwu, E.O.; Wang, Z.M. Titanium alloys and their machinability-A review. J. Mater. Process. Technol. 1997, 68, 262-274. [CrossRef]

6. Kikuchi, M.; Okuno, O. Machinability Evaluation of Titanium Alloys. Dent. Mater. J. 2011, 23, 37-45. [CrossRef]

7. Gupta, K.; Laubscher, R.F. Sustainable machining of titanium alloys: A critical review. Proc. Inst. Mech. Eng. Part B J. Eng. Manuf. 2017, 231, 2543-2560. [CrossRef]

8. Maruda, R.W.; Krolczyk, G.M.; Wojciechowski, S.; Zak, K.; Habrat, W.; Nieslony, P. Effects of extreme pressure and anti-wear additives on surface topography and tool wear during MQCL turning of AISI 1045 steel. J. Mech. Sci. Technol. 2018, 32, 1585-1591. [CrossRef]

9. Maruda, R.W.; Krolczyk, G.M.; Michalski, M.; Nieslony, P.; Wojciechowski, S. Structural and Microhardness Changes after Turning of the AISI 1045 Steel for Minimum Quantity Cooling Lubrication. J. Mater. Eng. Perform. 2017, 26, 431-438. [CrossRef]

10. Ginting, A.; Nouari, M. Surface integrity of dry machined titanium alloys. Int. J. Mach. Tools Manuf. 2009, 49, 325-332. [CrossRef]

11. Pramanik, A. Problems and solutions in machining of titanium alloys. Int. J. Adv. Manuf. Technol. 2014, 70, 919-928. [CrossRef]

12. Trujillo, F.J.; Sevilla, L.; Marcos, M. Experimental Parametric Model for Indirect Adhesion Wear Measurement in the Dry Turning of UNS A97075 (Al-Zn) Alloy. Materials 2017, 10, 152. [CrossRef] [PubMed]

13. Sánchez, Y.; Trujillo, F.J.; Bermudo, C.; Sevilla, L. Experimental Parametric Relationships for Chip Geometry in Dry Machining of the Ti6Al4V Alloy. Materials 2018, 11, 1260. [CrossRef] [PubMed]

14. Niknam, S.A.; Khettabi, R.; Songmene, V. Chapter 1 Machinability and Machining of Titanium Alloys:A Review BT-Machining of Titanium Alloys. In Machining of Titanium Alloys; Springer: Berlin/Heidelberg, Germany, 2014; pp. 1-30. ISBN 978-3-662-43901-2.

15. De Aguiar, M.M.; Diniz, A.E.; Pederiva, R. Correlating surface roughness, tool wear and tool vibration in the milling process of hardened steel using long slender tools. Int. J. Mach. Tools Manuf. 2013, 68, 1-10. [CrossRef]

16. Calamaz, M.; Coupard, D.; Girot, F. A new material model for 2D numerical simulation of serrated chip formation when machining titanium alloy Ti-6Al-4V. Int. J. Mach. Tools Manuf. 2008, 48, 275-288. [CrossRef]

17. Arrazola, P.-J.; Garay, A.; Iriarte, L.-M.; Armendia, M.; Marya, S.; Le Maître, F. Machinability of titanium alloys (Ti6Al4V and Ti555.3). J. Mater. Process. Technol. 2009, 209, 2223-2230. [CrossRef]

18. Nouari, M.; Makich, H. Analysis of Physical Cutting Mechanisms and Their Effects on the Tool Wear and Chip Formation Process When Machining Aeronautical Titanium Alloys: Ti-6Al-4V and Ti-55531. In Machining of Titanium Alloys; Springer: Berlin/Heidelberg, Germany, 2014; pp. 79-111. ISBN 978-3-662-43901-2.

19. Bejjani, R.; Odelros, S.; Kaplan, B.; Norgren, S.; Kritikos, M. Study of tool wear and chemical interaction during machining of Ti6Al4V. Int. J. Refract. Met. Hard Mater. 2017, 72, 253-256.

20. Su, Y.; Li, L.; Wang, G.; Zhong, X. Cutting mechanism and performance of high-speed machining of a titanium alloy using a super-hard textured tool. J. Manuf. Process. 2018, 34, 706-712. [CrossRef]

21. Liang, X.; Liu, Z.; Wang, B. State-of-the-art of surface integrity induced by tool wear effects in machining process of titanium and nickel alloys: A review. Meas. J. Int. Meas. Confed. 2019, 132, 150-181. [CrossRef]

22. Hatt, O.; Crawforth, P.; Jackson, M. On the mechanism of tool crater wear during titanium alloy machining. Wear 2017, 374-375, 15-20. [CrossRef]

23. Hatt, O.; Lomas, Z.; Thomas, M.; Jackson, M. The effect of titanium alloy chemistry on machining induced tool crater wear characteristics. Wear 2018, 408-409, 200-207. [CrossRef]

24. Chen, L.; El-Wardany, T.I.; Harris, W.C. Modelling the effects of flank wear land and chip formation on residual stresses. CIRP Ann. Manuf. Technol. 2004, 53, 95-98. [CrossRef]

25. Liang, L.; Liu, X.; Li, X.Q.; Li, Y.Y. Wear mechanisms of WC-10Ni3Al carbide tool in dry turning of Ti6Al4V. Int. J. Refract. Met. Hard Mater. 2015, 48, 272-285. [CrossRef]

26. Dimla, D.E. Sensor signals for tool-wear monitoring in metal cutting operations-A review of methods. Int. J. Mach. Tools Manuf. 2000, 40, 1073-1098. [CrossRef]

27. Ambhore, N.; Kamble, D.; Chinchanikar, S.; Wayal, V. Tool condition monitoring system: A review. Mater. Today Proc. 2015, 2, 3419-3428. [CrossRef]

28. Dimla, D.E.; Lister, P.M. On-line metal cutting tool condition monitoring. Int. J. Mach. Tools Manuf. 2002, 40, 739-768. [CrossRef]

29. Siddhpura, A.; Paurobally, R. A review of flank wear prediction methods for tool condition monitoring in a turning process. Int. J. Adv. Manuf. Technol. 2013, 40, 739-768. [CrossRef] 
30. Daymi, A.; Boujelbene, M.; Salem, S.B.; Hadj Sassi, B.; Torbaty, S.; Sassi, B.H. Effect of the cutting speed on the chip morphology and the cutting forces. Int. Sci. J. 2009, 1, 77-83.

31. Rosa, P.A.R.; Kolednik, O.; Martins, P.A.F.; Atkins, A.G. The transient beginning to machining and the transition to steady-state cutting. Int. J. Mach. Tools Manuf. 2007, 47, 1904-1915. [CrossRef]

32. Abdel Hamid, A.; Ali, Y. Experimental determination of dynamic forces during transient orthogonal cutting. J. Mater. Process. Technol. 1995, 55, 162-170. [CrossRef]

33. Calamaz, M.; Coupard, D.; Girot, F. Numerical simulation of titanium alloy dry machining with a strain softening constitutive law. Mach. Sci. Technol. 2010, 14, 244-257. [CrossRef]

34. Yameogo, D.; Haddag, B.; Makich, H.; Nouari, M. Prediction of the Cutting Forces and Chip Morphology When Machining the Ti6Al4V Alloy Using a Microstructural Coupled Model. Procedia CIRP 2017, 58, 335-340. [CrossRef]

35. Outeiro, J.C.; Umbrello, D.; M'Saoubi, R.; Jawahir, I. Evaluation of present numerical models for predicting metal cutting performance and residual stresses. Mach. Sci. Technol. 2015, 19, 183-216. [CrossRef]

36. Melkote, S.N.; Grzesik, W.; Outeiro, J.; Rech, J.; Schulze, V.; Attia, H.; Arrazola, P.J.; M'Saoubi, R.; Saldana, C. Advances in material and friction data for modelling of metal machining. CIRP Ann. Manuf. Technol. 2017, 66, 731-754. [CrossRef]

37. Arrazola, P.J.; Özel, T.; Umbrello, D.; Davies, M.; Jawahir, I.S. Recent advances in modelling of metal machining processes. CIRP Ann. Manuf. Technol. 2013, 62, 695-718. [CrossRef]

38. Trujillo, F.J.; Sevilla, L.; Marcos, M. Cutting speed-feed coupled experimental model for geometric deviations in the dry turning of UNS A97075 Al-Zn alloys. Adv. Mech. Eng. 2014, 2014, 1-11. [CrossRef]

39. Trujillo, F.J.; Sevilla, L.; Martín, F.; Bermudo, C. Analysis of the Chip Geometry in Dry Machining of Aeronautical Aluminum Alloys. Appl. Sci. 2017, 7, 132.

40. Yang, X.; Liu, C.R. Machining Science and Technology: An International Machining Titanium and Its Alloys; Taylor and Francis: London, UK, 2012; ISBN 1094034990894.

41. Hayajneh, M.T.; Astakhov, V.P.; Osman, M.O.M. An analytical evaluation of the cutting forces in orthogonal cutting using a dynamic model of the shear zone with parallel boundaries. J. Mater. Process. Technol. 1998, 82, 61-77. [CrossRef]

42. ISO. Tool-Life Testing with Single-Point Turning Tools; ISO: Geneva, Switzerland, 1993; Volume 3685, pp. 1-50.

43. Zoya, Z.; Krishnamurthy, R. The performance of CBN tools in the machining of titanium alloys. J. Mater. Process. Technol. 2000, 100, 80-86. [CrossRef] 